\title{
Sociodemography and Clinical Profile of COVID 19 Positive Physicians at a Tertiary Level Hospital, Dhaka
}

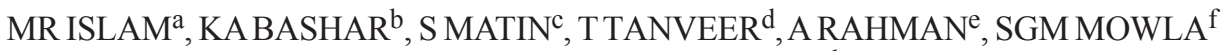 \\ KMM MURSHED $^{\mathrm{g}}$, UK BARUA ${ }^{\mathrm{h}}$
}

\begin{abstract}
:
Introduction: On 11 ${ }^{\text {th }}$ March, 2020 COVID19 was declared as a pandemic and it currently involves 210 countries worldwide. Bangladesh declared its first case on $8^{\text {th }}$ March 2020. Currently, the highest case detection of COVID is in the Dhaka district. Due to a lack of quality PPE (personal protection equipment) and proper knowledge of donning, doffing and transmission dynamics of COVID 19 thought to be high infection rate among physicians.
\end{abstract}

Material and Methods: A pretested questionnaire was set and distributed among COVID 19 infected physicians working at Shaheed Suhrawardy Medical College Hospital through internet to know about the clinical and epidemiological characteristics.

Results: $65.3 \%$ of the respondents were male and had a mean age were 35.7 years. Among all the respondents, the highest

\section{Introduction:}

Several cases of pneumonia of unknown etiology were reported in the city of Wuhan, Hubei province, china during December $2019^{1}$. The symptoms were dry cough, fever, fatigue, quickly developing shortness of breath and other respiratory symptoms. Researchers identified a new coronavirus with the use of real-time

a. Dr. Mohammad Rafiqul Islam, Associate Professor of Medicine, Shaheed Suhrawardy Medical College.

b. Dr. Khondaker Abul Bashar, Medical Officer, Shaheed Suhrawardy Medical College Hospital.

c. Dr. Shariful Matin, Registrar, Shaheed Suhrawardy Medical College Hospital

d. Tahmid Tanveer, Department of Environmental Science and Management, North South University.

e. Dr. Atiqur Rahman, Assistant Registrar, Shaheed Suhrawardy Medical College Hospital.

f. Dr Syed Ghulam Mogni Mowla, Associate Professor of Medicine, Dhaka Medical College.

g. Dr. K M Mamun Murshed, Associate Professor of ENT, Shaheed Suhrawardy Medical College.

h. Prof. Uttam Kumar Barua, Director, Shaheed Suhrawardy Medical College Hospital.

Address of Correspondence: Dr. Mohammad Rafiqul Islam, Associate Professor of Medicine, Shaheed Suhrawardy Medical College. Cell:01753199796, Mail: drrafiq73@yahoo.com number of physicians involved were from medicine department (26.9\%). Lethargy, body ache and fever were observed in $57.69 \%$, 50\% and 30.7\% patients respectively. Among 52 infected physicians, first time RT-PCR for COVID 19 yield 78.8\% positive results. Prophylactic dose of hydroxychloroquine taken by $15.3 \%$ patients before being infected with COVID19.

Conclusion: Health care workers are getting infected in a alarming number but fortunately at Shaheed Suhrawardy Medical college all the cases were in mild form.

Key word: COVID 19, RT-PCR, SARS-COV-2

(J Bangladesh Coll Phys Surg 2020; 38: 56-60) DOI: https://doi.org/10.3329/jbcps.v38i0. 47444

reverse transcription polymerase chain reaction (RTPCR), from bronchoalveolar lavage, labeled as Severe Acute Respiratory Syndrome Coronavirus 2 (SARSCoV-2), later also called coronavirus disease 2019 (COVID-19) ${ }^{2,3}$. World health organization (WHO) declared CoVID-19 a pandemic in March 11, 2020 because of the quick spreading nature of this highly contagious virus caused a global concern of worldwide public health issues ${ }^{4,5}$.

A rapid and robust response by the global scientific community described many important aspects of SARS$\mathrm{CoV}-2$ transmission and natural history ${ }^{6-8}$. Bangladesh declared its first three cases of COVID 19 on $8^{\text {th }}$ March $2020^{9}$ and as of $29^{\text {th }}$ May 2020, according to WHO there are 40321 confirmed COVID-19 cases in Bangladesh, including 559 related deaths and worldwide total 5701 337 cases and 357688 deaths ${ }^{10}$. Implementation of infection prevention and control (IPC) is of great importance in healthcare settings during the periods of outbreak of COVID-19 or other infectious diseases especially regarding personal protection of healthcare workers $^{11,12}$. Objective of our study was to analyze clinical and epidemiological data of RT-PCR positive COVID19 physicians at Shaheed Suhrawardy Medical College. 
Personal protection equipment was a key issue during the beginning of the epidemic. Awareness regarding personal protection, clear understanding of transmission of infection and preparedness of response were also lacking among health care workers. Wu et al. have reported the problems relating to COVID-19 IPC in healthcare settings, highlighting the personal protection of healthcare workers ${ }^{13}$.

\section{Material and Methods:}

We surveyed physicians from Shaheed Suhrawardy Medical College Hospital who were infected with COVID 19 by an online survey from $21^{\text {st }}$ May to $28^{\text {th }}$ May. The study was approved by ethical review committee of Shaheed Suhrawardy Medical College. An online based pretested questionnaire was set and distributed at an online platform where members of the group consisted of physicians of Shaheed Suhrawardy Medical College. All subjects provided informed consent before registration. Those who agreed to participate were given the questionnaire. Although more than 80 physicians were RT-PCR positive for COVID but only 52 physicians agreed to take part in the online based survey. The questionnaire consisted of a total of 11 questions. Age group, sex, working department, presentation, Rt PCR test, use of repurposing drugs, co-morbid condition and pregnancy were the key issues in the questionnaire. Total 52 physicians who are RT-PCR positive COVID19 patients responded. As all are count data, frequency and percentage were analyzed.

\section{Results:}

A total of 52 physicians responded out of 80 targeted RTPCR positive COVID patients to the online questionnaire. Male respondents were $65.3 \%$ and female $34.6 \%$. Participants were from different age group and mean age were 35.7 years. Predominant responders were from 3140 age group, who consisted of $50 \%$ of the data (Table I).

\section{Table-I}

Socio demographic profile of respondents

\begin{tabular}{llcc} 
Category & Group & Frequency & Percentage \\
\hline Gender & Male & 34 & 65.3 \\
& Female & 18 & 34.6 \\
Age group & $21-30$ & 14 & 26.9 \\
& $31-40$ & 26 & 50 \\
& $41-50$ & 9 & 17.3 \\
& $51-60$ & 3 & 5.76 \\
\hline
\end{tabular}

Shaheed Suhrawardy Medical College were a non COVID hospital during collection of data. Department wise distribution revealed more involvement in medicine department (26.9\%), with the gynecology department (21.1\%) following as second. Symptom analysis reveals lethargy $(57.69 \%)$ ranks top of the list and then body ache was observed in $50 \%$ of patients (Table II).

Table-II

\begin{tabular}{lcc} 
Distribution frequency & among different departments. \\
Category & Frequency & Percentage \\
\hline Medicine & 14 & 26.9 \\
Surgery & 7 & 13.4 \\
Gynecology & 11 & 21.1 \\
Pediatrics & 5 & 9.6 \\
ICU & 4 & 7.6 \\
Emergency & 3 & 5.7 \\
Pathology & 2 & 3.8 \\
Nephrology & 2 & 3.8 \\
Neurology & 2 & 3.8 \\
Cardiology & 1 & 1.9 \\
ENT & 1 & 1.9 \\
\hline
\end{tabular}

Fever was observed in $30.7 \%$ of patients and highest recorded temperature was $103^{\circ} \mathrm{F}$ that was observed in only one patient. Rest observed temperatures range between $99 \mathrm{~F}$ to $102^{\circ} \mathrm{F}$ inclusive. Figure 1 shows that $9.6 \%$ patients didn't have any symptoms.

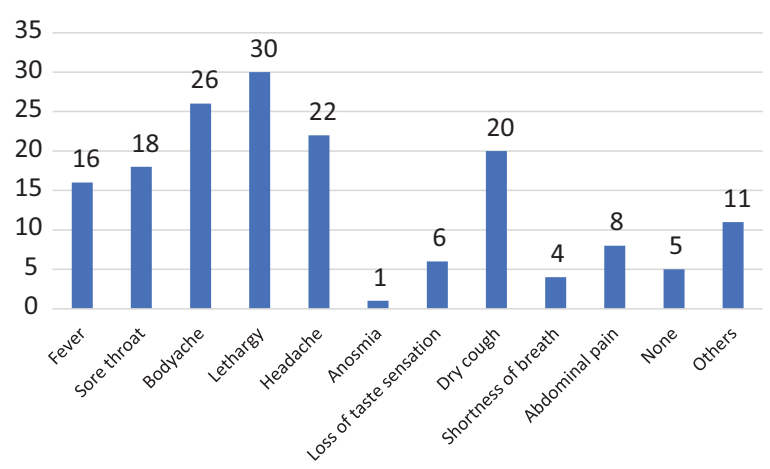

Fig.-1: Frequency of symptoms 
All of the respondents did their RT-PCR for COVID 19 either due to symptoms or because of having contact with infected or potentially infected patients. Among the respondents, $78.8 \%$ of patients got positive results in first time but $15.3 \%$ and $5.7 \%$ patients got their result positive after second time and third time respectively (Figure 2). They done second and third time due to having consistent symptom of COVID19.

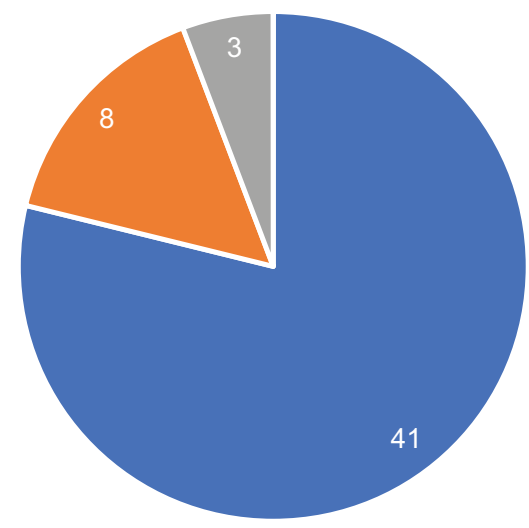

One time

Two times

Three times

Fig.-2: Frequency of RT-PCR tests to become COVID 19 positive

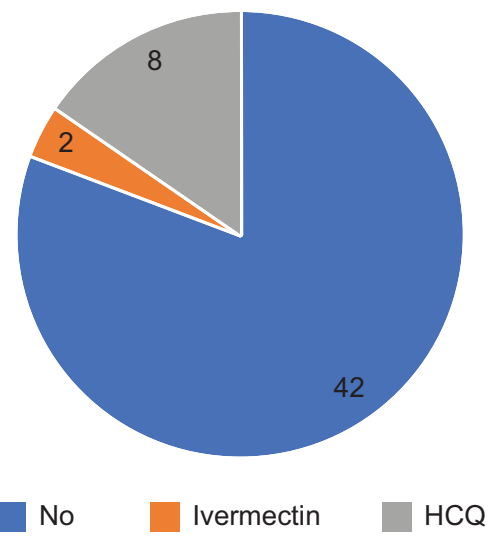

Fig.-3: Frequency of taking prophylaxis for COVID 19

Before becoming positive with COVID 19, 15.3\% patients took prophylactic dose of hydroxychloroquine and 3.8\% patients took ivermectin (Figure 3). Among all 52 patients, $11(21.1 \%)$ patients got admitted to hospital. Among them six (11.53\%) patients became hospitalized but didn't take any oxygen or medical treatment but four $(7.6 \%)$ patients took medical treatment but didn't get oxygen. Only one patient took low flow oxygen within the hospital set up.

Majority of respondents were of 31-40 years' age group. No comorbidity was present in $30(57.6 \%)$ patients. Dominant comorbidities were asthma in $10(19.23 \%)$, hypertension in $8(15.3 \%)$, diabetes in $2(3.8 \%)$, and hypothyroidism in $2(3.8 \%)$ patients. There was no comorbidity in $57.6 \%$ patients. Four patients were lactating mother and one was pregnant.

\section{Discussion:}

All of the respondents were COVID confirmed patients and everyone declared recovery after alleviation of symptoms and after two RT-PCR test yielded negative results. Male physicians (65.3\%) and 31-40 age group physicians were predominantly affected. In Italy, HCWs had a median age of 48 years, and $68 \%$ were female and $32 \%$ were male ${ }^{14}$.

According to IEDCR ${ }^{15}$, male female ratio of COVID patients are $71 \%$ to $29 \%$ and 21 to 30 age group tops with $27.6 \%$ and 31 to 40 age group $27.1 \%$. The data does not paint a complete picture however, as many suspected Covid 19 patients hide information in fear of isolation and social stigma ${ }^{16}$. As their premier symptoms of Covid 19 are fever and respiratory ailment, they get admitted to indoor medicine facilities since they hide their contacts and symptoms. Possibly that was one of the major reasons for more physicians from department of medicine became infected.

In Wuhan China, symptoms among healthcare workers were fatigue (60\%) and muscle pain (45.5\%) which is in line with our finding ${ }^{17}$. They also found $56.4 \%, 50 \%$ and $60.9 \%$ patients (healthcare workers) had cough, sore throat and fever respectively which is not in line with our findings ${ }^{17}$. Gupta $\mathrm{N}$ et al ${ }^{18}$ from India found fever, cough and sore throat in $42.9 \%, 42.9 \%$ and $23.8 \%$ which nearly matches with our findings. RT-PCR remains the gold standard for case detection. RT-PCR may yield false positive and false negative results. Proper collection, assessing peak viral load time, type of sample and storage procedure are important factors to get actual results.

False negative results may also come from mutations in the primer and probe target regions in the SARS-CoV-2 
genome. RT-PCR assay is designed as precisely as possible based on the conserved regions of the viral genomes, variability causing mismatches between the primers and probes and the target sequences can lead to decrease in assay performance and potential falsenegative results. In this regard, multiple target gene amplification could be used avoid invalid results ${ }^{19}$. Kucirka $\mathrm{LM}^{20}$ et al showed that on the day of symptom onset, the median false-negative rate was $38 \%$ (CI, $18 \%$ $65 \%)$. This decreased to $20 \%(\mathrm{CI}, 12 \%-30 \%)$ on day 8 (three days after symptom onset) then began to increase again, from $21 \%(\mathrm{CI}, 13 \%-31 \%)$ on day 9 . False negative result varies with days of performing RT-PCR. No specific pharmacological treatment is effective against COVID 19 and here chloroquine and chloroquine-related formulations have been tentatively used to limit the total burden of COVID ${ }^{21-22}$.

Within Bangladesh's national guideline for COVID 19 management (version 6) the prophylactic use of Hydroxychloroquine is recommended ${ }^{23}$. Thus, $15.3 \%$ patients took hydroxychloquine prophylactically and still they became infected. Comorbidity remains an important factor for case fatality. Juan $\mathrm{A}$ et $\mathrm{al}^{24}$ discovered after reviewing literature that $30 \%$ and $14 \%$ patients are hypertensive and diabetic respectively which do not align with our limited data. Premier comorbidity that we got is bronchial asthma in 10 (19.23\%) patients among covid 19 positive physicians though according to national asthma prevalence study (NAPS) revealed (5.2\%) population of Bangladesh suffering from asthma ${ }^{25}$. This is possibly because we received a limited data and large-scale study may alter our comorbidity findings.

\section{Limitation:}

This is a small-scale study on targeted population. Lab parameters were not included in this study. Large scale, multicentered study including lab parameter may represent actual scenario of the COVID pandemic in the country.

\section{Conclusion:}

Undoubtedly, physicians are the most important resource among all health care workers during a pandemic period. Infected physicians remain out of work for a prolonged period of time. This seriously hampers work environment as well as decreases the morale of healthy physicians. In our study all the cases were milder variety and dominant presentation was lethargy which should be focused. Suspected symptomatic patient should go for repeated testing and prophylaxis treatment before being infected doesn't work.

\section{References:}

1. Wang C, Horby PW, Hayden FG, Gao GF. A Novel Coronavirus Outbreak of Global Health Concern. The Lancet 2020;395(10223):470-473.

2. Zhu N, Zhang D, Wang W, Li X, Yang B, Song J. A Novel Coronavirus from Patients with Pneumonia in China, 2019. N Engl J Med. 2020;382(8):727-733

3. Jiang F, Deng L, Zhang L, Cai Y, Cheung CW, Xia Z. Review of the Clinical Characteristics of Coronavirus Disease 2019 (COVID-19). J Gen Intern Med. 2020;35(5):1545 1549 .

4. Zu Z, Jiang M, Xu P, Chen W, Ni Q, Lu G et al. Coronavirus Disease 2019 (COVID-19): A Perspective from China. Radiology. 2020;200490.

5. Zhu N, Zhang D, Wang W, Li X, Yang B, Song J, et al. A Novel Coronavirus from Patients with Pneumonia in China, 2019. N Engl J Med. 2020;382(8):727 733

6. Li Q, Guan X, Wu P, Wang X, Zhou L, Tong Y, et al. Early transmission dynamics in Wuhan, China, of novel coronavirus-infected pneumonia. $N$ Engl J Med 2020; 382: 1199-207

7. Chen N, Zhou M, Dong X, Qu J, Gong F, Han Y, et al. Epidemiological and clinical characteristics of 99 cases of 2019 novel coronavirus pneumonia in Wuhan, China: a descriptive study. Lancet 2020; 395: 507-13.

8. Lauer S, Grantz K, Bi Q, Jones F, Zheng Q, Meredith H et al. The Incubation Period of Coronavirus Disease 2019 (COVID-19) From Publicly Reported Confirmed Cases: Estimation and Application. Annals of Internal Medicine. 2020;172(9):577-582.

9. WHO Bangladesh COVID-19 Situation Report \#10. https:/ /www.who.int/bangladesh/emergencies/coronavirus-disease(covid-19)-update/coronavirus-disease-(covid-2019)bangladesh-situation-reports

10. WHO Bangladesh COVID-19 Situation Report \#130. https:/ /www.who.int/docs/default-source/coronaviruse/situationreports/20200529-covid-19-sitrep- 130.pdf? sfvrsn= bf7e7f0c_4

11. Wang J., Liu F., Tan J.B.X., Harbarth S., Pittet D., Zingg W. Implementation of infection prevention and control in acute care hospitals in Mainland China - a systematic review. Antimicrob Resist Infect Control. 2019; 8:32

12. Chang D, Xu H, Rebaza A, Sharma L, Dela Cruz C. Protecting health-care workers from subclinical coronavirus infection. The Lancet Respiratory Medicine. 2020;8(3):13. 
13. Wu A., Huang X., Li C., Li L. Novel coronavirus (2019nCov) pneumonia in medical institutions: problems in prevention and control. Chin J Infect Control. 2020; 19:16.

14. Lapolla, P. \& Mingoli, A. (2020). COVID-19 changes medical education in Italy: will other countries follow? ... Deaths from COVID-19 in healthcare workers in Italy what can we learn? Infection Control \& Hospital Epidemiology, 1-4.

15. IEDCR https://www.iedcr.gov.bd/index.php/component/ content/article/website/images/files/nCoV/Case_dist_1_ June_upload.pdf

16. Rahman Jahangir, A., 2020. Many coronavirus carriers in Bangladesh hiding info creating fresh problems. UNB News, [online] Available at: <https://unb.com.bd/category/ Bangladesh/many-coronavirus-carriers-in-bangladeshhiding-info-creating-fresh-problems/50300> [Accessed 23 April 2020].

17. Lai X, Wang M, Qin C, Tan L, Ran L, Chen D, et al. Coronavirus Disease 2019 (COVID-2019) Infection Among Health Care Workers and Implications for Prevention Measures in a Tertiary Hospital in Wuhan, China. JAMA Netw Open. 2020;3(5)

18. Gupta N, Agrawal S, Ish P, Mishra S, Gaind R, Usha G, et al. Clinical and epidemiologic profile of the initial COVID-19 patients at a tertiary care centre in India. Monaldi Archives for Chest Disease 2020; 90:1294
19. Tahamtan A, Ardebili A. Real-time RT-PCR in COVID-19 detection: issues affecting the results. Expert Rev Mol Diagn. 2020;20(5):453 454 .

20. Kucirka LM, Lauer SA, Laeyendecker O, Boon D, Lessler J. Variation in False-Negative Rate of Reverse Transcriptase Polymerase Chain Reaction-Based SARS-CoV-2 Tests by Time Since Exposure [published online ahead of print, 2020 May 13]. Ann Intern Med. 2020; M20-1495

21. Cortegiani A, Ingoglia G, Ippolito M, Giarratano A, Einav S. A systematic review on the efficacy and safety of chloroquine for the treatment of COVID-19 [published online ahead of print, 2020 Mar 10].

22. Yao X, Ye F, Zhang M, Cui C, Huang B, Niu P, et al. In Vitro Antiviral Activity and Projection of Optimized Dosing Design of Hydroxychloroquine for the Treatment of Severe Acute Respiratory Syndrome Coronavirus 2 (SARS-CoV2). Clin Infect Dis. 2020 Mar 9. [Epub ahead of print]

23. Ministry of Health \& Family Welfare, Government of the People's Republic of Bangladesh, 2020. National Guidelines On Clinical Management Of Coronavirus Disease 2019 (COVID-19). Dhaka: Disease Control Division, Directorate General of Health Services, p 27.

24. Juan A. Siordia J. Epidemiology and clinical features of COVID-19: A review of current literature. Journal of Clinical virology 127 (2020) 104357.

25. Asthma Association of Bangladesh. National guidelines Asthma \& COPD,2012;1-55 